\title{
GOVERNOS LOCAIS E GESTÃO DE POLITICAS SOCIAIS UNIVERSAIS
}

Celina Souza

\begin{abstract}
Resumo: Argumenta-se, neste artigo, que, apesar de a capacidade dos governos locais de proverem serviços sociais universais e de aumentarem formas de democracia participativa ser muito desigual, vários municípios vêm assumindo novos papéis na governança local como resultado de políticas federais e locais. A despeito dessa expansão do papel dos municípios, a sustentabilidade do atual sistema de governança local ainda não está clara.

Palavras-chave: governança local; políticas participativas; políticas sociais.
\end{abstract}

\begin{abstract}
It is discussed in this article that despite the capacity of the local government to provide universal social services and increase forms of participative democracy to be strongly unequal, several counties are taking on new roles in the local government as a result of federal and local politics. Despite this expansion of the counties, the sustainability of the present form of government is still unclear. Key words: local government; participative politics; social politics.
\end{abstract}

$\mathrm{D}$ esde a promulgação da Constituição de 1988, as instituições políticas brasileiras estão passando por profundas modificações. Essas mudanças criaram novas institucionalidades, principalmente na esfera local, resultado de compromissos gerados durante o processo de redemocratização. Entre esses compromissos estavam o de restaurar a Federação, através do aumento do poder político e tributário das entidades subnacionais, e o de consolidar a democracia, por meio do empoderamento (empowerment) das comunidades locais no processo decisório sobre políticas públicas. Essas mudanças foram engendradas por uma coalizão existente na Constituinte, formada por parlamentares que possuíam fortes laços com as demandas municipais. ${ }^{1} \mathrm{O}$ fato de a decisão de aumentar o papel dos governos e das comunidades locais ter ocorrido no âmbito da Constituinte mostra que, no caso brasileiro, a descentralização/municipalização está longe de ser uma questão de ordem exclusivamente administrativa, impulsionada, nos seus anos iniciais, pelo governo federal ou por organismos multilaterais, como tem sido em muitos países em desenvolvimento, mas sim uma questão eminentemente política. Do contrário, por que os constituintes brasileiros teriam se empenhado em promovê-la? No final dos anos 90, novas políticas voltadas para a municipalização foram adotadas, embora suas motivações tenham sido diversas daquelas que prevaleceram no processo constituinte, uma vez que seu principal decisor e indutor foi o próprio governo federal. Essas políticas transformaram os governos locais nos principais provedores dos serviços universais de saúde e educação fundamental.

$\mathrm{O}$ artigo descreve e analisa o sistema brasileiro de governança local pós-1988 e procura responder a dois conjuntos de questões: quais as principais inovações institucionais ocorridas após a redemocratização em relação aos governos e às comunidades locais e suas principais conseqüências sobre a governança local e a provisão de serviços sociais universais; e quais as condições de sustentabilidade dessas mudanças. A procura de resposta para essas questões pretende preencher a lacuna ainda existente na pesquisa empírica em políticas públicas realizada no Brasil, que focaliza, em geral, a distância entre os objetivos das mudanças e seus resultados ou analisa o impacto do desenho das novas políticas sobre o sistema federativo. A despeito da capacidade desigual dos governos locais brasileiros de proverem serviços públicos sociais e de aumen- 
tarem a democracia local, muitos estão promovendo mudanças na governança local, não só como resultado dos mandamentos constitucionais, dos posteriores incentivos criados pelo governo federal e das pressões dos organismos multilaterais, mas também por políticas desenhadas localmente. No entanto, o novo sistema de governança local materializa-se de forma desigual entre os municípios brasileiros e sua sustentabilidade ainda não está clara.

As seções seguintes analisam as finanças públicas locais, inclusive as mudanças promovidas pelas últimas emendas constitucionais, com especial ênfase no funcionamento das relações intergovernamentais entre as esferas federal e municipal. O conhecimento mais detalhado sobre as finanças públicas locais é importante porque os recursos à disposição da esfera local influenciam não só a governança local, mas também o provimento de serviços públicos universais. Em seguida, analisa-se o desenho das novas políticas introduzidas pelo governo federal nos anos 90, as quais criaram recompensas e sanções para induzir a adesão dos governos locais. Por último, o artigo discute as novas políticas voltadas para o empoderamento do poder decisório das comunidades locais.

\section{GOVERNOS LOCAIS PÓS-1988}

Apesar de no Brasil a definição oficial de município não fazer distinção entre a enorme diversidade dos 5.561 municípios, nem mesmo em relação ao grau de urbanização e à separação entre áreas urbanas e rurais, assim como entre a sede e os distritos municipais, existem diferenças marcantes entre eles. Assim, a definição oficial de muni- cípio torna-se uma ferramenta meramente administrativa, que independe da incorporação de variáveis importantes, principalmente o tamanho da localidade. ${ }^{2}$ Tal uniformidade também significa que as regras aplicadas aos governos locais são invariáveis e independem da complexidade das tarefas a eles atribuídas.

A importância relativa dos governos municipais no Brasil em termos financeiros vem sendo paulatinamente alcançada a cada nova Constituição federal, principalmente a partir da de 1988. Conforme notam Afonso e Araújo (2000:38), entre 1988 e 1998, o volume de recursos próprios dos municípios elevou-se em aproximadamente 197\%. Em 1998, a receita tributária municipal atingiu seu nível histórico máximo, cerca de $1,6 \%$ do PIB, ou R\$ 14 bilhões anuais. Os municípios elevaram sua participação no bolo tributário nacional de $11 \%$ para $17 \%$ nos dez primeiros anos de vigência do novo sistema, registrandose um pequeno declínio a partir do final dos anos 90 e, em 2003, os municípios detinham 16\% dos recursos tributários nacionais (Afonso, 2004:9). Do lado da despesa, os governos locais eram responsáveis, em 1999, por 19\% das despesas totais com pessoal, $39 \%$ das despesas correntes e pela metade dos gastos da Formação Bruta de Capital Fixo FBCF, esta última importante variável para analisar os dados de despesa, uma vez que mostra não só os gastos com investimento, mas também os compromissos futuros com despesas correntes (Afonso e Araújo, 2000:37-38).

Tais recursos, no entanto, são distribuídos de forma muito desigual, dadas as grandes heterogeneidades do país, que não são apenas socioeconômicas, mas também demográficas, como mostram os dados da Tabela 1.

TABELA 1

Principais Características Demográficas e Econômicas

Regiões do Brasil - 2000

\begin{tabular}{|c|c|c|c|c|c|c|c|}
\hline Regiões & População & $\begin{array}{c}\mathrm{N}^{0} \text { de } \\
\text { Municípios }\end{array}$ & $\begin{array}{l}\text { Área } \\
\left(\mathrm{km}^{2}\right)\end{array}$ & $\begin{array}{l}\text { Habitantes/ } \\
\text { Área }\end{array}$ & $\begin{array}{l}\text { Habitantes/ } \\
\text { Município }\end{array}$ & $\begin{array}{l}\text { Área }\left(\mathrm{km}^{2}\right) / \\
\text { Município }\end{array}$ & $\begin{array}{c}\text { PIB per } \\
\text { Capita - } 2001\end{array}$ \\
\hline Brasil & 169.590 .693 & 5.560 & 8.544 .402 & 19,8 & 30.500 & 1.536 & 6.954 \\
\hline Norte & 12.893 .561 & 449 & 3.869 .634 & 3,3 & 28.716 & 8.618 & 4.312 \\
\hline Nordeste & 47.693 .253 & 1.791 & 1.558 .196 & 30,6 & 26.629 & 870 & 3.255 \\
\hline Sul & 25.089 .783 & 1.189 & 577.213 & 43,4 & 21.100 & 485 & 8.387 \\
\hline Sudeste & 72.297 .351 & 1.668 & 927.284 & 78,0 & 43.343 & 555 & 9.316 \\
\hline Centro-Oeste & 11.616 .745 & 463 & 1.612 .075 & 7,2 & 25.090 & 3.481 & 7.260 \\
\hline
\end{tabular}

Fonte: <www.ibge.gov.br>. 
TABELA 2

Arrecadação Tributária Própria Municipal, segundo Faixas Populacionais Brasil- 1996

\begin{tabular}{|c|c|c|c|}
\hline $\begin{array}{l}\text { Faixas } \\
\text { Populacionais }\end{array}$ & $\begin{array}{c}\text { População } \\
\text { (mil habitantes) }\end{array}$ & $\begin{array}{c}\text { Receita } \\
\text { Tributária } \\
\text { (R\$ milhões) }\end{array}$ & $\begin{array}{c}\text { Receita } \\
\text { Tributária } \\
\text { per Capita }(\mathrm{R} \$)\end{array}$ \\
\hline Brasil & 147.834 & 10.497 & 71,0 \\
\hline Até 20.000 hab. & 28.418 & 415 & 14,6 \\
\hline Mais de 20.000 a 50.000 hab. & 25.360 & 575 & 22,7 \\
\hline Mais de 50.000 a 100.000 hab. & 18.210 & 697 & 38,3 \\
\hline Mais de 100.000 a 300.000 hab. & 23.726 & 1.443 & 60,8 \\
\hline Mais de 300.000 hab. & 16.685 & 1.519 & 91,0 \\
\hline Capitais & 35.435 & 5.847 & 165,0 \\
\hline Norte & 7.724 & 231,4 & 30,0 \\
\hline Até 20.000 hab. & 1.311 & 4,7 & 3,6 \\
\hline Mais de 20.000 a 50.000 hab. & 1.359 & 7,5 & 5,5 \\
\hline Mais de 50.000 a 100.000 hab. & 833 & 12,4 & 14,9 \\
\hline Mais de 100.000 a 300.000 hab. & 582 & 4,3 & 7,4 \\
\hline Mais de 300.000 hab. & 341 & 3,6 & 10,7 \\
\hline Capitais & 3.297 & 198,8 & 60,3 \\
\hline Nordeste & 41.210 & 870,9 & 21,1 \\
\hline Até 20.000 hab. & 9.698 & 23,3 & 2,4 \\
\hline Mais de 20.000 a 50.000 hab. & 10.269 & 42,2 & 4,1 \\
\hline Mais de 50.000 a 100.000 hab. & 5.723 & 45,3 & 7,9 \\
\hline Mais de 100.000 a 300.000 hab. & 4.528 & 66,0 & 14,6 \\
\hline Mais de 300.000 hab. & 1.675 & 50,8 & 30,3 \\
\hline Capitais & 9.316 & 643,2 & 69,0 \\
\hline Sudeste & 66.814 & $7.686,5$ & 115,0 \\
\hline Até 20.000 hab. & 8.375 & 204,3 & 24,4 \\
\hline Mais de 20.000 a 50.000 hab. & 8.079 & 348,9 & 43,2 \\
\hline Mais de 50.000 a 100.000 hab. & 7.165 & 453,7 & 63,3 \\
\hline Mais de 100.000 a 300.000 hab. & 12.230 & $1.030,2$ & 84,2 \\
\hline Mais de 300.000 hab. & 13.216 & $1.351,8$ & 102,3 \\
\hline Capitais & 17.748 & $4.297,6$ & 242,1 \\
\hline Sul & 23.492 & $1.364,0$ & 58,1 \\
\hline Até 20.000 hab. & 6.468 & 140,3 & 21,7 \\
\hline Mais de 20.000 a 50.000 hab. & 3.994 & 139,8 & 35,0 \\
\hline Mais de 50.000 a 100.000 hab. & 3.625 & 162,4 & 44,8 \\
\hline Mais de 100.000 a 300.000 hab. & 4.915 & 300,6 & 61,2 \\
\hline Mais de 300.000 hab. & 1.453 & 112,9 & 77,7 \\
\hline Capitais & 3.036 & 507,9 & 167,3 \\
\hline Centro-Oeste & 8.594 & 344,4 & 40,1 \\
\hline Até 20.000 hab. & 2.566 & 42,0 & 16,4 \\
\hline Mais de 20.000 a 50.000 hab. & 1.657 & 36,9 & 22,2 \\
\hline Mais de 50.000 a 100.000 hab. & 863 & 23,5 & 27,2 \\
\hline Mais de 100.000 a 300.000 hab. & 1.471 & 42,2 & 28,7 \\
\hline \multicolumn{4}{|l|}{ Mais de 300.000 hab. e } \\
\hline Capitais & 2.037 & 199,9 & 98,2 \\
\hline
\end{tabular}

Fonte: Adaptado de Afonso et al. (1999:35).
A receita própria municipal per capita, calculada por região e tamanho da população, também reflete as heterogeneidades mencionadas (Tabela 2).

Nas Tabelas 1 e 2, verificam-se as desigualdades entre os municípios, em todos os indicadores analisados. No entanto, essa diversidade não é explicada apenas pelas desigualdades entre as cinco regiões do país, dado que existem também grandes diferenças tanto dentro de uma mesma região como de um mesmo Estado. Tais diferenças podem ser vistas na distribuição dos municípios de acordo com o tamanho da população (Tabela 3). Trata-se de indicador importante porque afeta a capacidade de arrecadação do município.

As maiores diferenças na distribuição da população ocorrem no Nordeste, onde o número de pequenas municipalidades com populações entre 10.000 e 20.000 habitantes é bastante alto vis-à-vis as demais regiões. Isso mostra os constrangimentos financeiros desse grupo de municípios que abrigam populações muito pobres, o que impede o aumento das receitas próprias locais. Ademais, a Constituição alocou aos municípios o direito de tributar bens e serviços, cujo fato gerador decorre do ambiente urbano, o que privilegia os de maior porte demográfico. No que se refere às transferências estaduais, via ICMS (Imposto sobre Circulação de Mercadorias e Prestação de Serviços de Transporte Interestadual e Intermunicipal e de Comunicação), os municípios de pequeno porte também são penalizados, visto que essas transferências são calculadas de acordo com o volume arrecadado em cada município. Tais limitações são parcialmente compensadas pelas transferências federais via o Fundo de Participação dos Municípios - FPM.

Cálculos do Ibam (2001) mostram que os municípios com menos de 10.000 habitantes e aqueles com população entre 10.000 e 20.000 representam $74,8 \%$ do total de municípios do Brasil, sendo que a média da receita própria desses municípios representa $7 \%$ do total dos seus recursos. Somente nos municípios com população superior a 50.000 pessoas, a receita total e a receita própria estão acima da média encontrada no país, no entanto, representam apenas 9,5\% do total dos municípios brasileiros (Tabela 4).

No que se refere às competências municipais, a Constituição de 1988 optou pela ênfase nas competências concorrentes ou comuns entre os três níveis de governo (Quadro 1). Como será discutido adiante, os governos locais são hoje os principais provedores das ações de saúde pública e estão aumentando sua participação na educação fundamental como resultado de políticas induzidas por legislação federal e incentivos financeiros. 
TABELA 3

Distribuição dos Municípios, segundo Faixas Populacionais

Regiões do Brasil - 1999

\begin{tabular}{lcrrrrr}
\hline Grupos de & \multirow{2}{*}{ Brasil } & \multicolumn{3}{c}{ Grandes Regiões } \\
\cline { 3 - 7 } Habitantes & $\mathbf{5 . 5 0 7}$ & 449 & 1.787 & 1.666 & Sul & Centro-Oeste \\
\hline Total & 2.727 & 190 & 662 & 840 & 7.159 & 446 \\
Até 10.000 hab. & 1.392 & 112 & 588 & 344 & 243 & 253 \\
Mais de 10.000 a 20.000 hab. & 908 & 103 & 395 & 267 & 84 & 59 \\
Mais de 20.000 a 50.000 hab. & 279 & 30 & 96 & 106 & 30 & 17 \\
Mais de 50.000 a 100.000 hab. & 174 & 12 & 37 & 98 & 18 & 9 \\
Mais de 100.000 a 500.000 hab. & 27 & 2 & 9 & 11 & 2 & 3 \\
Mais de 500.000 hab. & & & & & & \\
\hline
\end{tabular}

Fonte: IBGE apud Ibam (2001:4).

TABELA 4

Distribuição das Receitas Médias dos Municípios, segundo Faixas Populacionais

Brasil-1998

$\mathrm{Em} \mathrm{R} \$ \mathrm{mil}$

\begin{tabular}{|c|c|c|c|c|}
\hline $\begin{array}{l}\text { Grupo de } \\
\text { Habitantes }\end{array}$ & $\begin{array}{c}\text { Receita } \\
\text { Total }\end{array}$ & $\begin{array}{c}\text { Receita } \\
\text { Tributária }\end{array}$ & $\begin{array}{l}\text { Transferências } \\
\text { Constitucionais }\end{array}$ & $\begin{array}{c}\text { Outras } \\
\text { Receitas }\end{array}$ \\
\hline Total & 12.514 & 2.721 & 7.700 & 2.093 \\
\hline Até 10.000 hab. & 2.919 & 188 & 2.122 & 609 \\
\hline Mais de 10.000 a 20.000 hab. & 5.160 & 398 & 3.941 & 821 \\
\hline Mais de 20.000 a 50.000 hab. & 9.785 & 1.172 & 7.198 & 1.415 \\
\hline Mais de 50.000 a 100.000 hab. & 23.878 & 4.107 & 16.568 & 3.163 \\
\hline Mais de 100.000 a 500.000 hab. & 92.372 & 23.876 & 57.413 & 11.083 \\
\hline Mais de 500.000 hab. & 776.176 & 265.967 & 333.587 & 176.619 \\
\hline
\end{tabular}

Fonte: Ibam (2001:5).

QUADRO 1

Competências Concorrentes e Competências Municipais

\begin{tabular}{ll}
\hline Esfera de Governo & \multicolumn{1}{c}{ Serviços/Atividades } \\
\hline Federal-estadual-local (competências partilhadas) & Saúde e assistência pública \\
& Assistência aos portadores de deficiência \\
& Preservação do patrimônio histórico, artístico e cultural \\
& Proteção do meio ambiente e dos recursos naturais \\
& Cultura, educação e ciência \\
& Preservação das florestas, da fauna e da flora \\
& Agricultura e abastecimento alimentar \\
& Habitação e saneamento \\
& Combate à pobreza e aos fatores de marginalização social \\
& Exploração das atividades hídricas e minerais \\
& Segurança do trânsito \\
Predominantemente local & Políticas para pequenas empresas \\
& Turismo e lazer \\
& Pré-escola e educação fundamental \\
Apenas local & Saúde \\
& Preservação histórica e cultural \\
& Transporte coletivo \\
\hline
\end{tabular}


Do ponto de vista político, os governos locais sempre foram instituições relevantes, particularmente os prefeitos. A distribuição dos partidos políticos que hoje governam as cidades também espelha a diversidade que caracteriza a instituição município no Brasil. Nas eleições de 2000, quando foram às urnas 92 milhões de eleitores, cresceu o número de municípios governados pelo PT, que, no período 2000-04, administrou 17 das 62 maiores cidades brasileiras, congregando um eleitorado de mais de 14 milhões de eleitores, embora o partido esteja administrando número relativamente pequeno de municípios (183), em comparação com os outros grandes partidos. O PMDB manteve a primeira posição entre os partidos que governam o maior número de cidades (1.218), seguido pelo PSDB (1.055) e PFL (1.009). As eleições de 2000 promoveram maior equilíbrio entre os partidos que administram os municípios, em comparação com as eleições municipais anteriores, nas quais o PFL e o PMDB controlavam a maioria dos Executivos locais, com exceção das grandes cidades.

Alguns novos instrumentos legais também vêm influenciando a institucionalidade dos municípios, tais como a exigência da Constituição de 1988 de que todos os municípios fossem regidos por Leis Orgânicas próprias. Mais recentemente, em 2001, o Estatuto da Cidade (Lei Federal no 10.257), aprovado após mais de dez anos de intensa negociação no Congresso, ampliou o papel do governo local no processo de desenvolvimento urbano e de gestão do território.

Analisar o papel que vem sendo desempenhado pelos governos locais, no que se refere ao estímulo ou constrangimento à instituição de mecanismos pluralistas e republicanos de gestão das cidades, assim como buscar padrões de gestão local e de implementação de políticas públicas e de provisão de serviços, não é tarefa fácil devido à diversidade existente entre os municípios brasileiros. No entanto, pode-se arriscar propor uma "tipologia" de gestão das cidades após a redemocratização, baseada em três "paradigmas" que, em geral, estão associados ao tipo de partido político que governa as cidades. O primeiro reflete a busca de eficiência na provisão dos serviços públicos locais, em que os resultados das políticas públicas assumem relevância diante dos processos de intermediação de interesses ou de cooperação entre grupos sociais distintos. O PFL está mais próximo desse "paradigma", sendo que cidades como Curitiba, Salvador e Rio de Janeiro seriam seus exemplos mais visíveis. O segundo está associado ao PT e sua ênfase recai no estímulo às políticas participativas, na linha do autogoverno, particularmente em questões que envolvem a alocação de recursos orçamentários. O terceiro, ainda importante apesar de abalado pelas iniciativas de algumas instituições formais, prevalece em cidades de pequeno, médio e grande portes, ricas ou pobres, e é aquele no qual as instituições políticas locais ainda são frágeis, dando espaço para políticas locais pouco universais e para formas de gestão pouco republicanas.

\section{ESTRUTURA DAS FINANÇAS PÚBLICAS LOCAIS}

Nenhuma Constituição anterior à de 1988 cedeu aos municípios o volume de recursos públicos de que agora dispõem. Tais recursos provêm, como se sabe, de transferências federais e estaduais, assim como de receitas próprias. O Quadro 2 mostra a estrutura da alocação de im-

QUADRO 2

Impostos Locais e Transferências Constitucionais

\begin{tabular}{lll}
\hline Recursos Próprios (1) & Transferências Federais (2) & \multicolumn{1}{c}{ Transferências Estaduais } \\
\hline - Imposto sobre Serviços de Qualquer Natureza (ISS) & - $22,5 \%$ do IR e do IPI (3) & • $25 \%$ do ICMS \\
- Imposto sobre a Propriedade Territorial e Predial Urbana (IPTU) & - $50 \%$ do ITR (4) & $\begin{array}{l}\text { - } 50 \% \text { do IPVA (Imposto Sobre a Propriedade de } \\
\text { Veículos Automotores) }\end{array}$ \\
- Imposto sobre Transmissão Inter-Vivos (ITBI) & & - $25 \%$ da parcela estadual da Cide (5) \\
\hline
\end{tabular}

(1) Os municípios podem cobrar taxas por seus serviços e contribuição de melhoria decorrente de obra pública. Pela EC 39/2002, os municípios também podem cobrar contribuição para o custeio do serviço de iluminação pública.

(2) Municípios produtores de recursos minerais, petróleo, gás natural e ouro têm participação nas arrecadações realizadas pelo governo federal, seja sob a forma de royalties seja no IOF (Imposto sobre Operações Financeiras).

(3) Encontra-se em discussão no Congresso o aumento para 23,5\% do percentual das transferências do IR e do IPI para os municípios.

(4) O município ficará com $100 \%$ do ITR se optar por ser responsável pela sua coleta, medida aprovada na EC 42/2003.

(5) Sobre a parcela da Cide a ser transferida para Estados e municípios, incide o bloqueio de $20 \%$ da DRU (Desvinculação das Receitas da União), ou seja, o percentual a ser transferido pela União não é integralmente transferido, tal como ocorre com os recursos federais vinculados à educação e à saúde, mas diferentemente das transferências do FPM e FPE, que, desde 2000, estão isentas desse bloqueio. 
postos destinados aos municípios após a Constituição de 1988 e suas posteriores emendas, inclusive a Emenda Constitucional no 42, aprovada em 19/12/2003, que introduziu mudanças no sistema tributário nacional. Por essa emenda, os municípios passaram a ter participação na Cide - Contribuição de Intervenção no Domínio Econômico, juntamente com os Estados.

Apesar de grandes desigualdades financeiras, existe um consenso de que o Brasil é um dos países mais descentralizados do mundo em desenvolvimento, porém, a descentralização financeira vem beneficiando mais os municípios do que os Estados. Em 2001, os governos locais administraram cerca de $12,5 \%$ dos recursos públicos nacionais, incluindo recursos próprios e as principais transferências constitucionais. Quando as receitas vinculadas a determinados programas são adicionadas, a parcela dos recursos nacionais à disposição dos municípios eleva-se para $15,5 \%$, como mostra a Tabela 5 .

\section{Transferências Constitucionais}

As transferências constitucionais advindas do IR e do IPI compõem o FPM - Fundo de Participação dos Municípios, no percentual de $22,5 \%$ sobre o total arrecadado nesses dois impostos federais. Do FPM, 10\% são transferidos para as capitais, $86,4 \%$ para os municípios do interior e 3,6\% para aqueles com mais de 156.216 habitantes. Essa fórmula de transferência beneficia, assim, os municípios menos populosos.

As transferências federais representam a principal fonte de receita para os municípios pequenos e médios, ou seja, aqueles que abrigam os mais pobres e com população mais rarefeita. Já as transferências do ICMS são a principal fonte de receita para os municípios economicamente mais desenvolvidos. O mecanismo de transferência do ICMS é determinado pela Constituição: cada município recebe 3/4 do que for coletado na sua jurisdição e o Estado pode determinar, por lei ordinária, os critérios de transferência para o percentual restante.

Quando a Constituição de 1988 foi promulgada, um dos principais objetivos dos constituintes, no que se refere ao sistema fiscal, foi conceder ampla liberdade aos entes federativos na determinação sobre onde e como aplicar seus recursos. A única restrição para as esferas subnacionais era o percentual de $25 \%$ da receita que deveria ser aplicado em educação. No entanto, a partir de meados dos anos 90, emendas constitucionais foram aprovadas, vinculando parte dos recursos transferidos a alocações específicas, em particular para os programas de saúde e educação fundamental, assim como foram introduzidas limitações ao poder das esferas subnacionais de decidir sobre a aplicação dos recursos. Em 1996, foi aprovada a Emenda Constitucional 14, vinculando recursos federais, estaduais e municipais à educação fundamental ${ }^{3}$ e, em 2002, a Emenda Constitucional 29 aprovou novas vinculações, dessa vez para os programas de saúde. ${ }^{4} \mathrm{O}$ impacto dessas mudanças sobre a governança local será analisado adiante. A Lei de Responsabilidade Fiscal, promulgada em 2000, também coloca limites na capacidade de despesa dos municípios e vários dispositivos legais impõem restrições à sua capacidade de endividamento.

Apesar de restrições recentes na sua autonomia financeira, os municípios são os maiores beneficiados das transferências federais, que representam $4,4 \%$ do PIB, enquanto

TABELA 5

Divisão da Receita Tributária, por Esfera de Governo

Brasil - 1989-2001

Em porcentagem

\begin{tabular}{|c|c|c|c|c|c|c|c|c|c|c|}
\hline \multirow{3}{*}{ Período } & \multirow{3}{*}{$\begin{array}{c}\text { Carga } \\
\text { Tributária (1) }\end{array}$} & \multirow{3}{*}{ Total } & \multicolumn{8}{|c|}{ Divisão da Receita Tributária } \\
\hline & & & \multicolumn{2}{|c|}{ Própria } & \multicolumn{3}{|c|}{ Disponível (2) } & \multicolumn{3}{|c|}{ Disponível Ampliada (3) } \\
\hline & & & União & Estados & União & Estados & Municípios & União & Estados & Municípios \\
\hline Junho/1989 & 21,9 & 100,0 & 72,4 & 27,6 & 65,2 & 23,9 & 10,9 & - & - & - \\
\hline Junho/1997 & 27,0 & 100,0 & 71,8 & 28,2 & 62,2 & 25,7 & 12,1 & 59,4 & 26,9 & 13,7 \\
\hline Junho/1998 & 26,7 & 100,0 & 73,2 & 26,8 & 62,3 & 25,2 & 12,5 & 59,0 & 26,8 & 14,2 \\
\hline Junho/1999 & 28,7 & 100,0 & 74,4 & 25,6 & 63,0 & 24,2 & 12,7 & 58,8 & 25,7 & 15,5 \\
\hline Junho/2000 & 30,0 & 100,0 & 74,2 & 25,8 & 63,4 & 23,9 & 12,6 & 59,7 & 25,1 & 15,2 \\
\hline Junho/2001 & 30,9 & 100,0 & 72,9 & 27,1 & 62,2 & 24,9 & 12,9 & 58,3 & 26,2 & 15,5 \\
\hline
\end{tabular}

Fonte: Termômetro da Descentralização. Disponível em: <http://federativo.bndes.gov.br>.

(1) Não inclui a arrecadação tributária dos municípios. A receita própria da União e dos Estados abrange $90 \%$ da carga tributária global.

(2) Receita Tributária Disponível = Arrecadação Direta +/- Transferências Constitucionais (apenas as principais transferências).

(3) Receita Tributária Disponível Ampliada = Receita Tributária Disponível +/- Transferências Voluntárias (apenas as federais). 
os Estados retêm 3,3\% das transferências. O montante destinado aos municípios representa o triplo do que arrecadam diretamente (Afonso, 2004:12).

\section{Recursos Próprios}

Apesar de as transferências estaduais e federais representarem a maior parcela dos recursos locais, as receitas próprias municipais equivalem a 1,6\% do PIB, ou seja, $4,8 \%$ do total dos recursos públicos nacionais ( $\mathrm{R} \$ 19.324$ milhões), sendo o governo federal responsável por $67,3 \%$ das receitas, ou 27,9\% do PIB, e os Estados por 27,9\%, ou $9,5 \%$ do PIB. ${ }^{5}$

Dos impostos próprios locais, o ISS é o mais importante em termos absolutos, representando, em 2001, 1,8\% dos principais impostos do país, ou $0,6 \%$ do PIB (em torno de R \$ 7.213 milhões). Apesar dessa importância, o ISS não é a principal fonte de receita dos municípios, nem mesmo dos economicamente mais dinâmicos. ${ }^{6}$ O ISS incide apenas sobre determinados tipos de serviços, em geral associados à urbanização. Esses serviços são listados em lei federal, mas cada município é autônomo para determinar, por lei municipal, suas alíquotas. Assim como o ICMS gerou o que ficou conhecido como "guerra fiscal", o mesmo ocorreu na esfera local com o ISS, principalmente entre municípios vizinhos ou próximos das capitais. Pressões dos prefeitos das capitais fizeram com que o Executivo federal, na Emenda Constitucional 37/2002, avocasse a si a competência para, através de lei complementar, além de fixar alíquotas máximas e mínimas, "regular a forma e as condições como isenções, incentivos e benefícios fiscais serão concedidos e revogados" (Art. 156:III). Essa lei complementar, de n. 116, promulgada em $31 / 7 / 2003$, fixou o teto de $5 \%$ como alíquota máxima do ISS e em seu artigo 4 busca coibir a guerra fiscal, ao determinar que só será considerado passível de tributação o local onde o contribuinte desenvolva suas atividades, "sendo irrelevantes para caracterizá-lo as denominações de sede, filial, agência", etc. Essa lei também ampliou a lista de serviços passíveis de pagamento de ISS, de cerca de 100 para aproximadamente 180 .

O IPTU é o segundo maior imposto local, representando, em 2001, 0,5\% do PIB e 1,4\% dos principais impostos do país, com uma arrecadação de R 5.619 milhões. Os municípios são livres para adotarem diferentes fórmulas e critérios para calcular o valor do imposto, desde que aprovados por lei municipal. O IPTU é o único imposto local que pode ser cobrado progressivamente. No entan- to, até 2002, várias decisões judiciais negavam a constitucionalidade da cobrança progressiva, que, segundo o Judiciário, se restringia ao critério do valor do imóvel. Os juízes argumentavam que a Constituição não deixava claro que a progressividade poderia incluir também o local de situação do imóvel e o seu uso. A Emenda Constitucional 29/2000 explicitou que o IPTU poderia ter alíquotas diferenciadas não só em razão do valor do imóvel, mas também de sua localização e uso. No entanto, o IPTU é o imposto com maior índice de evasão. Pesquisa do IBGE mostrou que, em 1998, apenas 12,6\% dos municípios conseguiram cobrar $80 \%$ do imposto devido e que a maioria coleta cerca de $50 \%$. Os municípios com população acima de 100.000 habitantes são os que apresentam os índices mais baixos de evasão (Ibam, 2001).

Apesar do aumento relativo das receitas locais e de avanços na estruturação de um novo sistema tributário, a arrecadação local de tributos apresenta várias limitações. Primeiro, o sistema tributário nacional é concentrado em impostos que incidem sobre a produção, vendas e consumo, os quais não estão sob a jurisdição municipal. Segundo, os impostos locais, principalmente o ISS e o IPTU, requerem a existência de bancos de dados, cadastros e atualizações dispendiosos e complexos, além de incidirem sobre um grande universo de contribuintes, em particular de pequenos negócios, como é o caso do ISS. Terceiro, os impostos locais apresentam limitações em países como o Brasil, onde os níveis de pobreza são altos e os serviços passíveis de cobrança de ISS ou não existem em pequenas localidades ou são de pequeno porte e instáveis.

\section{Outras Transferências Federais}

Além das transferências constitucionais, os governos locais recebem recursos federais para a implementação de algumas políticas sociais universais, tendo essa modalidade de transferências se ampliado a partir dos anos $90 .^{7}$ A Tabela 6 discrimina essas transferências para Estados e municípios, em 2000, mostrando que os governos locais são hoje os principais provedores dos serviços de saúde pública.

O aumento da receita dos governos locais representou, em termos agregados, maior participação dessa esfera de governo nas despesas sociais, mesmo antes dos efeitos das emendas constitucionais da saúde e da educação.

Apesar de o governo federal permanecer com a maior parcela da despesa social, 65\% dos seus gastos na área social são destinados ao sistema previdenciário. A despe- 
sa social segundo regiões mostra que as menos desenvolvidas economicamente apresentam valores per capita duas vezes menores do que as mais desenvolvidas (Tabela 7). No entanto, os três níveis de governo vêm aumentando a despesa social em regiões mais pobres ao longo do tempo. No Nordeste, por exemplo, o gasto social per capita alcançou $30 \%$ do PIB da região, enquanto no Norte correspondeu a $19,5 \%$, no Sudeste a $18,1 \%$, no Sul a $17,8 \%$ e no Centro-Oeste a 22\% (Draibe, 1999).

\section{POLÍTICAS DE MUNICIPALIZAÇÃO DE PROGRAMAS SOCIAIS UNIVERSAIS}

Diferentemente do que muitos analistas apontam, a descentralização no Brasil está longe de ser abrangente. Na verdade, esta vem se concentrando em dois campos: no aumento dos recursos financeiros para os municípios garantidos pela Constituição de 1988 e no aumento progressivo das transferências federais, a partir do final dos anos 90, para a implementação de alguns programas sociais universais. Assim, embora a descentralização tenha sido um dos objetivos dos constituintes de 1988, desenvolvimentos recentes apontam para a consolidação de políticas voltadas para a implementação de políticas sociais e não para o aumento da capacidade de decidir sobre onde e como investir os recursos.

Apesar da existência de grandes heterogeneidades entre os municípios, evidências empíricas mostram que, no agregado, os governos locais estão de fato substituindo o governo federal em algumas funções, enquanto outras se encontram em uma espécie de vazio governamental, seja por causa da política federal de ajuste fiscal, seja porque o desenho da política a ser municipalizada não contemplou incentivos capazes de estimular a adesão dos municípios.

\section{O Papel do Governo Local na Provisão de Serviços Sociais Universais}

Como já mencionado, as desigualdades inter e intraregionais dificultam a participação dos governos locais na provisão de serviços sociais universais. Políticas para superar os constrangimentos financeiros e de gestão da maioria dos municípios brasileiros foram engendradas pelo governo federal através da adoção de novos desenhos e formas de financiamento dessas políticas, que visam a municipalização da provisão da saúde pública e da educação fundamental.

Antes da introdução desses novos desenhos, era comum a acusação de que a Constituição de 1988 havia transferido recursos, mas não competências, para os governos subnacionais e de que a União havia perdido receitas embora continuasse com as mesmas responsabilidades, as quais não podiam ser transferidas para as esferas subnacionais, que passaram a contar com maior volume de receitas. No entanto, a experiência brasileira está demonstrando que a questão da transferência de responsabilidade pela provisão de serviços sociais universais não se restringe à existência de mais recursos financeiros para serem alocados livremente pelos governos locais e tampouco a determi-

TABELA 6

Total das Transferências Federais, para Estados e Municípios, segundo Tipos

Brasil -2000

Em R\$ milhão

\begin{tabular}{lrr}
\hline Tipos de Transferência & \multicolumn{1}{c}{ Estado } & Município \\
\hline Total & $\mathbf{3 0 . 3 0 7 . 3 6 7 . 6 4 8}$ & $\mathbf{2 7 . 8 3 0 . 3 7 3 . 8 4 1}$ \\
Transferências Constitucionais & 15.735 .280 .117 & 12.839 .573 .843 \\
Saúde & 1.729 .933 .548 & 7.251 .558 .677 \\
Compensação pela Isenção de ICMS (1) & 2.463 .300 .095 & $\mathbf{2 1 . 0 9 9 . 6 9 6}$ \\
Educação Fundamental & 3.046 .696 .710 & 2.820 .963 .476 \\
Distrito Federal e Antigos Territórios (2) & 2.617 .740 .084 & - \\
Royalties pela Extração de Minérios, Petróleo e Gás Natural & 1.082 .528 .089 & 1.064 .887 .546 \\
Outras Transferências & 3.631 .898 .005 & 3.032 .290 .603 \\
\hline
\end{tabular}

Fonte: Lima (2002:7).

(1) Transferências decorrentes da chamada Lei Kandir, criada em 1996 para compensar Estados e municípios pela perda de receita do ICMS de produtos exportados.

(2) Nos antigos territórios transformados em estados pela Constituição de 1988, o governo federal permanece responsável pelo financiamento de algumas funçóes públicas, assim como no Distrito Federal. 
nações constitucionais. As pesquisas vêm mostrando que a variável mais importante para que a descentralização ocorra é o desenho institucional da política.

A questão do desenho institucional tem recebido atenção crescente no que se refere ao seu papel nas políticas públicas. Dependendo de suas características, o desenho institucional pode ser decisivo no incentivo ou no constrangimento à descentralização. A municipalização da provisão dos serviços universais de saúde e educação fundamental, já inequívoca ou em processo acelerado de ampliação, parece comprovar esse argumento. Ambas as políticas foram concebidas como um sistema complexo de relações intergovernamentais baseado em recompensas e sanções. Tal sistema tornou racional para os municípios a adesão a uma nova institucionalidade. Como demonstra Arretche (2000), a transferência de responsabilidade pela implementação depende de estratégias indutivas desenhadas para delegar a implementação de uma dada política a outro nível de governo, de forma a superar os obstáculos à descentralização, que derivam de fatores estruturais e institucionais. Fatores de ordem gerencial também influenciam essa transferência.

A municipalização das políticas de saúde e educação pode ser considerada um sucesso nacional em termos quantitativos, enquanto saneamento, habitação e assistência social não obtiveram o mesmo resultado. Arretche (2000) argumenta que a falência dessas últimas políticas pode ser explicada pelos altos custos envolvidos na descentralização, tanto para Estados como para municípios, seja pela escassez de recursos (caso do saneamento), pelo alto débito acumulado (caso da habitação) ou pela ausência de repasses regulares de recursos (caso da assistência social). Além disso, nessas políticas, o desenho institucional não contemplou mecanismos de recompensas e sanções caso os governos subnacionais não aderissem a elas. Apesar de o governo federal ter tomado várias iniciativas voltadas para a descentralização dessas políticas, inclusive patrocinando novas legislações, o desenho institucional não contemplou nem a injeção de recursos novos, que é o caso da saúde, nem a possibilidade de perda relativa de recursos, que é o caso da educação.

Em contraste com o que aconteceu com as políticas de saneamento, habitação e assistência social, os governos locais responderam positivamente aos incentivos à municipalização da saúde e da educação. Isto pode ser creditado, no primeiro caso, à injeção de recursos adicionais nos cofres locais e, no segundo à penalidade para o município que não aumentar as matrículas nas escolas municipais, ao mesmo tempo em que também injeta mais recursos nas comunidades locais mais pobres, pois a política suplementa o salário dos professores nos municípios mais carentes.

A Tabela 8 mostra o aumento no número de municípios que aderiram à municipalização da saúde, que teve início em 1991, alcançando, em 2000, 98,96\% dos municípios. Com a adesão, $66 \%$ dos municípios passaram a receber recursos adicionais e em apenas $22 \%$ os efeitos da municipalização sobre os recursos locais foram neutros (Costa, Silva e Ribeiro, 1999:45).

Na política de saúde, a municipalização teve início com medidas de caráter meramente administrativo, mas que criaram regras claras e universais para as transferências, o que reduzia a incerteza, o grau de politização e partidarização no uso dos recursos e os riscos envolvidos para a adesão do município. Somente em 2000, quase dez anos após o início do programa e quando o sistema já estava consolidado, foi que o Executivo encaminhou ao Congresso proposta de emenda constitucional vinculando parcela dos recursos federais, estaduais e municipais ao programa de saúde. ${ }^{8}$ Apesar de ter havido redução dos recursos federais para programas sociais com a política

TABELA 7

Distribuição da Despesa Social, segundo Nível de Governo Brasil - 1980-1996

\begin{tabular}{|c|c|c|c|c|c|c|c|}
\hline & & & & & & & Em porcentagem \\
\hline $\begin{array}{l}\text { Nível de } \\
\text { Governo }\end{array}$ & 1980 & 1985 & 1992 & 1994 & 1995 & 1996 & $\begin{array}{c}\text { Média } \\
1994 / 1996\end{array}$ \\
\hline Total & 100,0 & 100,0 & 100,0 & 100,0 & 100,0 & 100,0 & 100,0 \\
\hline Federal & 66,0 & 62,0 & 57,0 & 60,0 & 59,0 & 57,0 & 59,0 \\
\hline Estadual & 24,0 & 25,0 & 26,0 & 23,0 & 24,0 & 23,0 & 24,0 \\
\hline Municipal & 11,0 & 13,0 & 16,0 & 16,0 & 17,0 & 19,0 & 18,0 \\
\hline
\end{tabular}

Fonte: Oliveira (1999). 
de ajuste fiscal, os recursos federais para a saúde vêm se mantendo relativamente constantes, como mostra a Tabela $9 .{ }^{9}$

Os incentivos do governo federal para a municipalização da educação fundamental seguiram caminho diverso do da saúde. No caso da educação, existe muito pouco "dinheiro novo" no caixa municipal, diferentemente da saúde, exceto nos municípios de Estados mais pobres. A distribuição dos recursos, condicionada à matrícula nas escolas estaduais ou municipais, é feita pelo Fundef e, quando o aluno desliga-se da escola estadual e matriculase na municipal, o município passa a receber o "valor" dessa matrícula, uma vez que as regras foram concebidas para remunerar o nível de governo que presta o serviço ao aluno, ou seja, o recurso acompanha o aluno. A adesão dos governos locais à municipalização da educação vem aumentando, embora não na mesma proporção do que ocorreu na saúde. No caso da educação, o incentivo assume a forma de sanção e não de recompensa, dado que o município tem que contribuir para o Fundef mesmo que o aluno não esteja matriculado na rede municipal. Além disso, $60 \%$ dos recursos do Fundef são vinculados ao pagamento de salários dos professores, o que também incentiva a municipalização em municípios de Estados pobres.

Com o novo desenho do programa de educação fundamental, a matrícula nesse nível de ensino vem crescendo nos últimos anos. No Norte e no Nordeste, os governos locais já são os principais provedores da educação fundamental e, em 2000, a matrícula em escolas municipais superou a das estaduais em todo o país, mas não em todos os Estados e regiões, atingindo 51\%, enquanto em 1997 o percentual era de $40,7 \%$ (Tabela 10 ).

O Fundef foi criado em 1996, pela Emenda Constitucional 14, regulamentado em 1997 e entrando em vigor em 1998. Do mesmo modo como na saúde, o desenho da municipalização da educação fundamental está ancorado em princípios claros e universais sobre as regras do jogo, válidas por dez anos, com as quais os diversos atores irão

TABELA 8

Municipalização da Saúde

Brasil - 1988-2000

\begin{tabular}{lcccc}
\hline Discriminação & 1988 & 1993 & 1996 & 2000 \\
\hline Número de Municípios que Aderiram à Municipalização & - & 670 & 3.127 & 5.450 \\
Total de Municípios & - & - & 4.973 & 5.507 \\
$\%$ de Municipalização & - & - & 62,9 & 99,0 \\
\hline
\end{tabular}

Fonte: <www.datasus.gov.br>.

TABELA 9

Porcentagem do PIB Gasto com Saúde, por Nível de Governo

Brasil - 1995-99

\begin{tabular}{|c|c|c|c|c|c|c|c|c|}
\hline \multirow[b]{3}{*}{ Anos } & & & & & & & & porce \\
\hline & \multicolumn{4}{|c|}{ Despesa Total (1) } & \multicolumn{4}{|c|}{ Despesa Financiada com Recursos Próprios (2) } \\
\hline & Federal & Estadual & Local & Total & Federal & Estadual & Local & Total \\
\hline 1995 & 0,9 & 0,9 & 2,1 & 3,9 & 2,3 & 0,5 & 1,0 & 3,0 \\
\hline 1996 & 0,7 & 0,9 & 1,7 & 3,3 & 1,8 & 0,6 & 0,8 & 3,3 \\
\hline 1997 & 0,8 & 0,9 & 2,0 & 3,7 & 2,2 & 0,5 & 1,0 & 3,7 \\
\hline 1998 & 0,8 & 0,9 & 1,9 & 3,7 & 2,1 & 0,6 & 1,0 & 3,7 \\
\hline 1999 (3) & 0,8 & 0,9 & 1,9 & 3,7 & 2,1 & 0,6 & 1,0 & 3,7 \\
\hline
\end{tabular}

Fonte: BNDES (2001).

(1) Financiada com recursos próprios e transferências federais.

(2) Apenas recursos próprios.

(3) Dados preliminares 
TABELA 10

Taxas de Matrícula no Ensino Fundamental, por Nível de Governo

Regiões do Brasil - 1997-2000

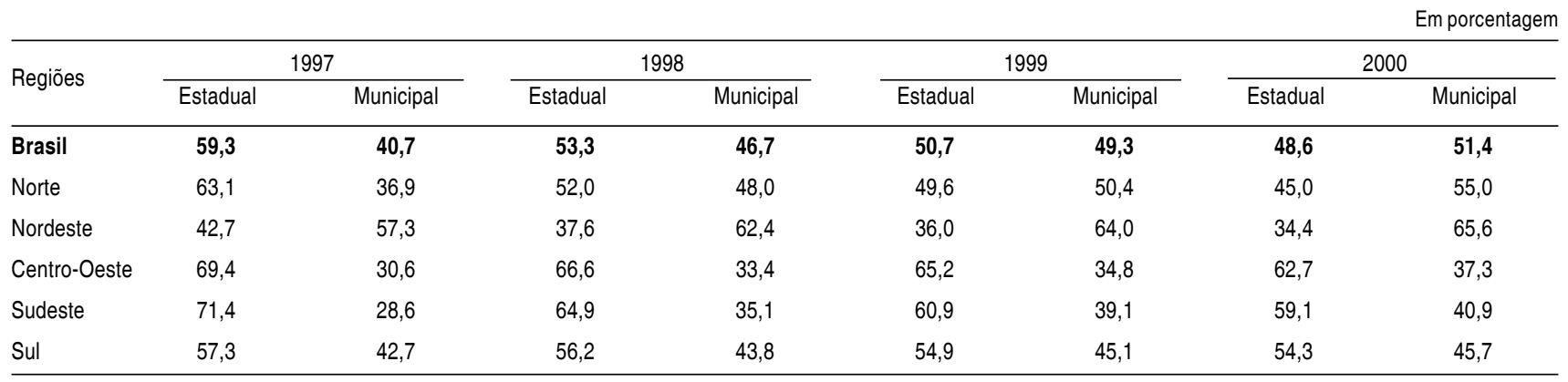

Fonte: <www.mec.gov.br>.

atuar. ${ }^{10}$ Além disso, e diferentemente da saúde, o desenho da municipalização do ensino fundamental tem um caráter redistributivo do ponto de vista regional, devido à existência de um teto mínimo a ser despendido com cada aluno e, quando os recursos vinculados das esferas estadual e municipal não atingem esse mínimo, o governo federal suplementa a diferença. Essa suplementação vem ocorrendo em todos os Estados do Nordeste e no Pará. ${ }^{11}$

Não deve ser esquecido, por fim, que, além do desenho institucional, os resultados positivos desses dois programas de municipalização também devem ser creditados ao fato de os dois Ministérios responsáveis pelo seu desenho e implementação terem sido ocupados por ministros próximos ao presidente da República. Não por acaso um desses ministros, o da Saúde, foi o candidato do governo às eleições presidenciais de 2002 e o da Educação também pleiteou a indicação de seu partido, o PSDB, à sucessão presidencial.

Em resumo, a experiência brasileira mostra que determinações constitucionais, normas, interesses de grupos ou capacidade gerencial e financeira, embora importantes, não foram suficientes para deslocar a implementação de políticas universais para as esferas locais. O desenho institucional da política - moldado em torno de mecanismos de recompensas e sanções, regras claras e universais - e o apoio do Executivo federal na liberação regular dos recursos parecem ser as variáveis mais importantes para a transferência de responsabilidades de implementação para os governos locais. Esses resultados mostram que a descentralização/municipalização no Brasil não implicou a transferência de capacidade decisória para as esferas subnacionais, mas sim na delegação de responsabilidade sobre a implementação de algumas políticas sociais univer- sais, o que não é tarefa fácil para milhares de municípios brasileiros. A experiência brasileira também mostra que as relações intergovernamentais evoluíram para um sistema lubrificado por recompensas e sanções, o que reduziu o grau de conflito entre os níveis de governo, mas, ao mesmo tempo, restringiu a autonomia de gasto e de decisão concedida aos governos locais pela Constituição de 1988.

A experiência brasileira mostra que a indução de políticas e recursos federais é fator fundamental para que os governos locais assumam o papel de provedores de serviços sociais universais. No entanto, algumas questões, velhas e novas, trazem dúvidas sobre a sustentabilidade dessa nova governança local e sobre sua trajetória futura. A primeira é que o governo federal vem aumentando sua participação na receita total, desde meados dos anos 90, criando novas contribuições e aumentando as alíquotas das existentes; em ambos os casos, os novos recursos não são constitucionalmente partilhados com os demais níveis de governo. A segunda é que a legislação que vincula receita dos três níveis de governo a serviços sociais universais precisará ser submetida à renovação, via novas emendas constitucionais, que requerem quorum qualificado. A terceira, relacionada com o que se vislumbra como uma nova tendência do governo federal que assumiu em 2003, fortalecida pela criação do Ministério de Desenvolvimento Social e Combate à Fome, é que a ênfase da política social parece estar sendo deslocada de políticas sociais universais providas pelos municípios para programas de transferência de renda centralizados na instância federal, em que os municípios parecem ter, até o momento, papel secundário e cujo desenho institucional prioriza os fóruns comunitários locais. Ademais, ainda não se vislumbram 
medidas voltadas para enfrentar os graves problemas de qualidade dos serviços universais providos pelas esferas locais. Assim como ocorreu com a transferência pela prestação desses serviços, o papel indutor do governo federal parece ser decisivo para que políticas voltadas para a qualidade dos serviços sejam iniciadas.

\section{EMPODERAMENTO DAS COMUNIDADES LOCAIS}

A municipalização de alguns serviços sociais universais, que gerou novas institucionalidades na governança local, não se limita à transferência de sua implementação, mas tem significado também o envolvimento das comunidades locais no processo decisório e de controle da implementação de políticas sociais. A Constituição de 1988 foi pródiga na criação de mecanismos de participação das comunidades locais em alguns fóruns decisórios e no controle dos resultados de certas políticas públicas locais, buscando, ao mesmo tempo, empoderar segmentos da comunidade e promover a accountability dos gestores públicos. Como resultado, muitos governos locais estão implementando ou consolidando várias experiências participativas, que vão desde conselhos municipais setoriais voltados para a decisão, participação na gestão e fiscalização de políticas sociais e de pequenas obras públicas, até a incorporação de segmentos sociais marginalizados do processo decisório na alocação de parcela dos recursos orçamentários locais, através do que ficou conhecido como Orçamento Participativo - OP.

No entanto, a inserção de novos atores ao processo decisório local assume formatos diferenciados. Existem experiências nas quais prevalecem formas mais restritas de participação, que se resumem a dar voz aos cidadãos, enquanto em outras a participação torna-se um mecanismo de empoderamento que visa promover mudanças na assimetria de poder entre atores sociais locais. Esse último formato visa, via ação coletiva, diminuir desigualdades políticas e sociais. ${ }^{12}$

Esses diferentes formatos geram três tipos de fóruns participativos. O primeiro ocorre nos conselhos municipais setoriais voltados para políticas específicas e onde os representantes dos cidadãos e/ou dos usuários dos serviços têm assento. Nesse formato, os representantes possuem, em princípio, não só a capacidade de expressar suas preferências (voz), mas também poder na gestão direta do programa (empoderamento) e no controle dos gestores públicos quanto ao cumprimento das decisões (accountability). Nesse formato, os programas e projetos são decididos, em geral, em outras instâncias, cabendo aos representantes poder de gestão e fiscalização. O segundo ocorre pela capacidade delegada aos cidadãos de decidir onde e como alocar parcela dos recursos orçamentários municipais, que se materializa nas diversas experiências de OP. ${ }^{13} \mathrm{O}$ terceiro ocorre nos chamados programas demand-driven, que se realizam em comunidades rurais pobres, em geral financiados por organismos multilaterais ou internacionais, e nos quais os representantes das comunidades decidem sobre a realização de obras comunitárias.

\section{Conselhos Municipais Setoriais}

A constituição desses conselhos decorre, em geral, de exigências da legislação federal. O papel dos conselheiros é tomar parte na gestão do programa, ou seja, fiscalizar a implementação de políticas decididas em outras esferas, alocar parcela dos recursos e acompanhar sua aplicação e os rumos da política pública. Para cada política social, é requerida a constituição de um conselho, em que os representantes da comunidade/usuários têm assento. Esses conselhos podem ser constituídos em torno de políticas específicas (saúde, educação, assistência social, emprego e renda, meio ambiente, desenvolvimento urbano, combate às drogas e à pobreza, etc.), ou em torno da defesa de direitos individuais ou coletivos (crianças, adolescentes, idosos, negros, deficientes, etc.). Segundo o IBGE, existiam no Brasil, em 2001, mais de 22.000 conselhos municipais, com predominância dos conselhos de saúde (5.426), assistência social (5.178), direitos das crianças e adolescentes (4.306) e educação (4.072).

De acordo com vários trabalhos, a existência dos conselhos é insuficiente para tornar seus participantes, especialmente os que representam interesses coletivos ou dos usuários do serviço, em decisores de fato e em fiscais da aplicação dos recursos. Côrtes (2002) apresenta uma tipologia dos conselhos municipais setoriais baseada em pesquisa empírica. O primeiro tipo é formado por conselhos que se transformaram em arenas decisórias de fato, visto que seus participantes têm papel decisório efetivo e não apenas voz. O segundo é constituído por conselheiros que atuam como intermediários de diferentes demandas e interesses, mas o decisor principal é o governo local. O terceiro é composto por especialistas reformistas (policy community), que têm espaço nos conselhos para expressar suas demandas, mas carecem de poder decisó- 
rio efetivo; nesse tipo, as decisões são tomadas em outros espaços, seja na esfera do governo ou dos grupos de interesse. Pode-se ainda acrescentar um quarto tipo, não incomum nas comunidades pequenas e pobres, em que muitas vezes os membros do conselho são indicados pelos dirigentes locais, principalmente o prefeito, e seu papel é o de ratificar as decisões tomadas pelo Executivo local.

\section{Orçamento Participativo}

Diferentemente dos conselhos municipais setoriais, a adoção de formas de Orçamento Participativo - OP não foi induzida por legislação federal ou organismos multilaterais, sendo uma iniciativa dos próprios governos locais. No entanto, assim como acontece com os conselhos municipais setoriais, o OP é uma opção dos governantes, ou seja, trata-se de uma política top-down, embora decidida localmente. As diversas experiências de OP assumiram grande visibilidade nacional e internacional, sendo apontadas como exemplos de boa governança. Devido a essa visibilidade, o OP propagou-se de forma crescente: no período 1986-98, foram registradas apenas duas experiências, em 1989-92 esse número aumentou para 12, em 1993-96 alcançou 36 e em 2000 o OP existia em 140 cidades (FNPP, 2002). Dessas experiências, 80 tiveram início em 1998, impulsionadas pela divulgação do OP de Porto Alegre.

Estruturado como um mecanismo participativo que incorpora membros da comunidade local ao processo decisório sobre a alocação de parcela dos recursos orçamentários locais, o OP não é isento de controvérsias, além de requerer a combinação de inúmeras variáveis. Uma pesquisa nacional, que analisou diversas experiências, concluiu que vários fatores influenciam nos resultados do OP, tais como:

- tipo de partido político que o implementa;

- nível de organização, mobilização e politização da sociedade;

- características socioeconômicas e demográficas do município;

- capacidade técnica e gerencial da administração local;

- compromisso do governo;

- situação financeira do município; e

- método adotado para estabelecer a relação entre governo e comunidade (FNPP, 2002).
A pesquisa também identificou que o OP é uma experiência instável: no período analisado, 23 administrações locais cancelaram suas experiências, número superior das que a adotaram no mesmo período, ou seja, nove. ${ }^{14}$ Argumenta-se, ainda, que o OP minimiza os custos do governo de negociar com as elites locais o provimento de infra-estrutura para os bairros mais pobres, diminuindo a distância entre estes e os bairros de classe média (IDB, 2003).

\section{Programas Demand-Driven}

Esses programas são financiados, em geral, pelos Fundos Municipais de Apoio Comunitário - Fumac, constituídos nos municípios mais pobres do Nordeste e que se destinam à realização de projetos/obras de pequeno porte. ${ }^{15}$ Nesses programas, os recursos são diretamente transferidos para as comunidades locais, que tomam decisões sobre onde e como aplicá-los, assim como são responsáveis também pela sua fiscalização. O objetivo é que a própria comunidade decida quais obras serão realizadas (demand-driven), em oposição a decisões tomadas em outras esferas (supply-driven). Existem ainda poucas avaliações sobre esses programas no Brasil, em especial a respeito de seu efetivo funcionamento nos diferentes municípios do Nordeste. Ao que parece, a análise mais completa é a de Judith Tendler (2000), que, apoiada em evidências coletadas em alguns Estados da região, aponta inúmeros problemas de implementação e demonstra ceticismo quanto ao atingimento dos seus objetivos.

Em resumo, experiências participativas têm sido abundantes nos territórios locais brasileiros nas duas últimas décadas. Estimuladas por legislação federal, pelos organismos multilaterais ou pelos próprios governos locais, o Brasil tem sido considerado um laboratório dessas experiências, que apontam para a tentativa de conciliação de duas visões rivais sobre o papel dos governos locais. $\mathrm{Na}$ primeira, o governo local seria o principal provedor de serviços sociais universais, enquanto, na segunda, seria o lócus privilegiado para a prática da democracia deliberativa, a ser alcançada por um relativo equilíbrio entre quem decide e quem é afetado pelas decisões.

\section{COMENTÁRIOS FINAIS}

Este trabalho mostrou que a experiência brasileira de governança local tem sido marcada por forte inovação institucional e por um complexo sistema de relações in- 
tergovernamentais, principalmente entre a União e os governos municipais. Tais inovações decorreram, no início, dos compromissos assumidos durante a redemocratização e, posteriormente, por decisões tomadas pelos próprios governos, tanto o federal como o local, muitas vezes impulsionadas pelos organismos multilaterais de financiamento de programas sociais. Apesar da capacidade desigual dos municípios brasileiros em tomarem parte nessa nova institucionalidade, existem indicações que apontam para mudanças na forma como a governança local está ocorrendo. No entanto, e apesar do maior envolvimento dos governos e das comunidades locais na provisão de serviços sociais universais e de bens públicos de uso comum, ainda não está claro se essas novas institucionalidades são sustentáveis sem o apoio financeiro e indutor do governo federal e de outros organismos exógenos à governança local.

\section{NOTAS}

Este artigo é uma versão revista e atualizada de um trabalho que integra a pesquisa Building Municipal Capacity for Finance and Budgeting, coordenada pelo International Development Department da School of Public Policy da Universidade de Birmingham (GB). Agradecimentos a José Roberto Afonso, a Richard Batley e a Walter Macedo pelos comentários e sugestões.

1. Melo (1993) analisa a penetração dos interesses municipais na Constituinte de 1946 e Souza (1997; 2001a e b) na de 1988.

2. Por esse critério, o grau de urbanização do país passou de $45 \%$ em 1960 para $81,25 \%$ em 2000 .

3. Até 2007 , os municípios têm que aplicar $15 \%$ das transferências do ICMS e do FPM na educação fundamental.

4. Os municípios devem alocar $15 \%$ de suas receitas próprias e de suas transferências constitucionais ao programa de saúde. O percentual de cada nível de governo deve ser revisto a cada cinco anos.

5. Dados coletados em: <http://federativo.bndes.gov.br>.

6. A cidade de São Paulo, por exemplo, apesar de gerar um volume de ISS maior do que 17 Estados brasileiros coletam de ICMS, tem como sua principal fonte de receita a transferência do ICMS.

7. Existem também transferências do governo federal para as esferas subnacionais, conhecidas como transferências negociadas. Essa modalidade, que canalizou muitos recursos no passado, inclusive durante o regime militar, perdeu importância relativa e absoluta, devido à política de ajuste fiscal, sendo hoje responsável por apenas $10 \%$ do total das transferências federais para Estados e municípios (Lima, 2002).

8. Importante registrar que muitas leis orgânicas municipais aprovadas em 1990 já previam a vinculação de parcela das receitas locais às ações de saúde.

9. A municipalização da saúde também influenciou a constituição de consórcios intermunicipais, gerando novas relações entre governos do mesmo nível. Segundo o IBGE, existiam, em 2001, 1.969 consórcios municipais de saúde. Áreas como meio ambiente e desenvolvimento econômico também têm sido objeto de criação de consórcios.
10. Por "regras do jogo", entendam-se os constrangimentos (limites) impostos aos atores em suas escolhas estratégicas.

11. Sobre o papel redistributivo da municipalização da educação, ver Rezende e Oliveira (2003).

12. Sobre esse ponto, ver Melo (2003) e Souza (2001a e b).

13. Na experiência brasileira de empoderamento, existem, ainda, outros formatos que incorporam apenas a voz dos cidadãos, tais como as audiências públicas.

14. A literatura sobre OP no Brasil é extensa. Para uma crítica sobre as limitações teórico-metodológicas de experiências participativas em geral, ver Kapoor (2002).

15. Esses programas são conhecidos como Fundos Sociais e têm o apoio financeiro do Banco Mundial, do BID e de organismos europeus. Foram iniciados na América Latina nos anos 80, mas hoje estão disseminados em 40 países da América Latina, África, Europa Oriental e Ásia. Segundo Tendler (2000), já foram destinados a esses programas mais de US\$ 3 bilhões.

\section{REFERÊNCIAS BIBLIOGRÁFICAS}

AFONSO, J.R. Brasil, um caso à parte. In: XVI Regional Seminar on Fiscal Policy. Santiago, 2004

AFONSO, J.R.; ARAÚJO, E. A capacidade de gastos dos municípios brasileiros: arrecadação própria e receita disponível. In: NEVES, G. et al. (Orgs.). Os municípios e as eleições de 2000. São Paulo: Konrad Adenauer Stiftung, 2000. p.35-56.

AFONSO, J.R. et al. Municípios, arrecadação e administração tributária: quebrando tabus. BNDES, 1999. (Relatório).

ARRETCHE, M. Estado federativo e políticas sociais: determinantes da descentralização. São Paulo: Revan, 2000.

BNDES - Banco Nacional de Desenvolvimento Econômico e Social. Municípios: os bons resultados orçamentários de 2000. Informe-se, n. 33, 2001.

CÔRTES, S. Viabilizando a participação em conselhos de política pública municipais: arcabouço institucional, organização do movimento popular e policy communities. In: XXV Encontro Anual da ANPOCS. Caxambu, 2002.

COSTA, N.R.; SILVA, P.L.B.; RIBEIRO, J.M. A descentralização do sistema de saúde no Brasil. Revista do Serviço Público, Rio de Janeiro, v.50, n.3, p.33-56, 1999.

DRAIBE, S. Brasil, anos 90: as políticas sociais no marco das reformas estruturais. São Paulo: Unicamp/Nepp, 1999. (Relatório).

FNPP - Fórum Nacional de Participação Popular. Experiências de orçamento participativo no Brasil: período 1997-2000. Rio de Janeiro: FNPP, 2002.

IBAM - Instituto Brasileiro de Administração Municipal. Evolução do quadro municipal brasileiro no período entre 1980 e 2001. Rio de Janeiro: Ibam, 2001 (Série Estudos Especiais, n. 20).

IDB - Inter-American Development Bank. Assessment of participatory budgeting in Brazil. IDB, 2003. (Relatório).

KAPOOR, I. The devil's in the theory: a critical assessment of Robert Chambers' work on participatory development. Third World Quarterly, v.23, n.1, p.101-117, 2002.

LIMA, E.C.P. Transferências da União para estados e municípios não originárias de repartição de receitas: para que se destinam e o que determina o montante. Brasília: Ipea, 2002. 
MELO, M.A. Municipalismo, nation-building e a modernização do Estado no Brasil. Revista Brasileira de Ciências Sociais, v.23, n.8, p.83-100, 1993.

Empowerment e governança no Brasil: questões conceituais e análise preliminar de experiências selecionadas. Recife: 2003. (Relatório).

OLIVEIRA, F. de. Evolução, determinantes e dinâmica do gasto social no Brasil: 1980/1996. Brasília: Ipea, 1999.

REZENDE, F.; OLIVEIRA, F.A. (Orgs.). Descentralização e federalismo fiscal no Brasil: desafios da reforma tributária. Rio de Janeiro: Konrad Adenauer Stifung, 2003.

SOUZA, C. Federalismo e descentralização na Constituição de 1988: processo decisório, conflitos e alianças. Dados, v.44, n.3, p.513560, 2001a.
. Construção e consolidação de instituições democráticas: papel do orçamento participativo. São Paulo em Perspectiva, v.15, n.4, p.84-97, out./dez. 2001 b.

Constitutional engineering in Brazil: the politics of federalism and decentralization. Houndmills e London: Macmillan; New York: St. Martin's Press, 1997.

TENDLER, J. Why are social funds so popular? In: YUSUF, S.; WU, W.; EVERETT, S. (Eds.). Local dynamics in the era of globalization. Oxford: Oxford University Press for the World Bank, 2000. p.114-129.

Celina Souza: Pesquisadora do Centro de Recursos Humanos da Universidade Federal da Bahia (celina@ufba.br). 